\title{
Effects of combined inspiratory muscle and cycle ergometer training on exercise performance in patients with COPD
}

\author{
Th. Wanke*, D. Formanek*, H. Lahrmann**, H. Brath*, \\ M. Wild*, Ch. Wagner*, H. Zwick*
}

Effects of combined inspiratory muscle and cycle ergometer training on exercise performance in patients with COPD. Th. Wanke, D. Formanek, H. Lahrmann, H. Brath, M. Wild, Ch. Wagner, H. Zwick. CERS Journals Ltd 1994.

ABSTRACT: Cycle ergometer training plays an important role in the rehabilitation of patients with chronic obstructive pulmonary disease (COPD), but the usefulness of specific inspiratory muscle training as part of pulmonary rehabilitation remains uncertain.

To determine whether inspiratory muscle training could intensify the known beneficial effects of cycle ergometer training on exercise performance in these patients, we compared the effect of an 8 week inspiratory muscle training combined with cycle ergometer training with that of an 8 week cycle ergometer training alone on inspiratory muscle performance and general exercise capacity. Patients were randomly assigned to the two training groups; 21 patients received additional inspiratory muscle training (Group 1) and 21 did not (Group 2). Maximal sniff assessed oesophageal and transdiaphragmatic pressures served as parameters for global inspiratory muscle strength and diaphragmatic strength, respectively. The duration for which the patient could breathe against a constant inspiratory pressure load was used as an index of inspiratory muscle endurance. Exercise capacity was determined by an incremental symptom-limited cycle ergometer test.

After the training period, inspiratory muscle performance improved significantly in the patients with inspiratory muscle training, but not in those without. Both training regimens increased maximal power output and oxygen uptake, but this improvement was significantly greater in the patients with inspiratory muscle training than in those without.

We conclude that inspiratory muscle training in addition to cycle ergometer training, can intensify the beneficial effects of cycle ergometer training on exercise performance in COPD patients.

Eur Respir J., 1994, 7, 2205-2211.
*Pulmonary Dept and L. Boltzmann-Institute for Environmental Research, Lainz Hospital, and **Dept of Physics, Technical University, Vienna, Austria.

Correspondence: Th. Wanke

Pulmonary Dept

Lainz Hospital

Wolkersbergenstr. 1

A-1130 Vienna

Austria

Keywords: Chronic obstructive pulmonary disease

exercise performance

inspiratory muscle function

inspiratory muscle training

Received: May 41994

Accepted after revision August 241994

This study was supported by the "Jubilee Funds of the Austrian National Bank" under the project No. 4342.
To improve physical capacity is one of the main aims of rehabilitation programmes for patients with chronic obstructive pulmonary disease (COPD) [1]. Exercise reconditioning has been shown to increase work tolerance and reduce dyspnoea $[2,3]$. It is an essential component of pulmonary rehabilitation [4]. Some authors have also mentioned specific training of the respiratory muscles for improving physical endurance in COPD patients [5-8]. The reason for using inspiratory muscle training (IMT) is that the respiratory muscles of COPD patients are suspected to be weak and their exercise tolerance is limited. Therefore, successful training of the respiratory muscles should increase maximal exercise ventilation and improve exercise capacity. However, there are many doubts about the use of such specific training for three very different reasons, depending on whether the respiratory muscles of the COPD patients are considered weak, chronically fatigued or normal: 1) If they are weak, they may already be close to their fatiguing threshold, since the mechanical load on these muscles is increased due to lung function abnormalities. Any further increase in the work of breathing by IMT may, therefore, not strengthen the inspiratory muscles but, on the contrary, be potentially hazardous. IMT is thought to be dangerous in patients with neuromuscular diseases and in patients with COPD $[9,10]$, because a weakened muscle is more susceptible to damage and fibre splitting [10]. 2) If they are chronically fatigued, rest and not training should be the treatment to improve respiratory muscle function [11]. 3) It probably makes no sense to train respiratory muscles if their function is well-preserved [12].

General exercise training is a cornerstone of rehabilitation programmes for patients with COPD for improving 
their exercise capacity. In itself, it increases the mechanical load on the ventilatory muscles by increasing the level of ventilation. When IMT is added, it may have an extra theoretical benefit on exercise tolerance, or may be hazardous by causing "overwork weakness" of the respiratory muscles, or may have no extra effect at all.

The purpose of our study was to determine whether combining general exercise training with specific respiratory muscle training is of value.

\section{Methods}

\section{Patient characteristics}

For the purpose of this study, we define chronic airflow obstruction as clinically stable primary pulmonary disease with the following features: 1) ratio of forced expiratory volume in one second to forced vital capacity $\left(\mathrm{FEV}_{1} / \mathrm{FVC}\right)$ of less than $70 \%$; 2$)$ total lung capacity (TLC) greater than $80 \%$ of the predicted value; and 3) change in $\mathrm{FEV}_{1}$ after bronchodilator inhalation of less than $15 \%$. The ventilatory limitation of exercise is defined as: a) a maximal heart rate that is below two standard deviations of the predicted maximal heart rate; $b$ ) an exercise ventilation that is higher than $80 \%$ of the maximal voluntary ventilation (MVV); and c) dyspnoea without other limiting symptoms at maximal exercise [13].

Sixty ambulatory patients, 39 men and 21 women, each fulfilling the study's definitions of chronic airflow obstruction and ventilatory limitation of exercise, were recruited for the study. Their respiratory impairment ranged from mild to severe [14]. None of them had evidence of endocrine, orthopaedic or primary cardiac disorders. Patients with clinical or electrocardiographic evidence of coronary artery disease, hypertension or cor pulmonale were excluded. Chronic medications included aminophylline and inhaled beta-adrenergic agents in all patients. The serum aminophylline level was in the therapeutic range in each patient. No patient was on oral steroids. Before entering the study, the patients were randomly assigned to either receive or not receive specific inspiratory muscle training in addition to cycle ergometer training. All patients gave informed consent for participation in this study, which was approved by the local Ethics Committee.

\section{Measurements}

Lung function. Lung function analysis consisted of spirometry and plethysmography. Spirometry was performed using an open system with integration of the flow signal; whole-body plethysmography was carried out by the constant volume method (Jaeger, Würzburg, Germany). The patients' lung function parameters were compared with the reference values given by the European Community for Steel and Coal [15].
Exercise testing. Progressive incremental tests were performed on an electrically-braked cycle ergometer (Jaeger, Würzburg, Germany), whilst the patient breathed room air. Each patient sat at rest on the bicycle for 4 min. Work rate was then increased by 10 or $25 \mathrm{~W}$ every $2 \mathrm{~min}$, until the patient was unable to continue cycling. If the $\mathrm{FEV}_{1}$ of the patient was less than $1 l$, the increment in power was $10 \mathrm{~W}$; if it was greater than $1 l$, the increment was $25 \mathrm{~W}$. Minute ventilation $\left(\dot{\mathrm{V}}_{\mathrm{E}}\right)$, tidal volume $\left(\mathrm{V}_{\mathrm{T}}\right)$, breathing frequency $\left(f_{\mathrm{R}}\right)$, oxygen uptake $\left(\dot{\mathrm{V}}_{\mathrm{O}_{2}}\right)$ and carbon dioxide output were measured from the analysis of the expirate every $30 \mathrm{~s}$ by using a computerized system (EOS Sprint, Jaeger, Würzburg, Germany). This system features pneumotachographic airflow measurement and a mixing chamber for metabolic rate measurement. Heart rate was monitored throughout the test. Capillary blood from the hyperaemic earlobe was taken at rest and at maximal exercise to estimate arterial oxygen $\left(\mathrm{PaO}_{2}\right)$ and carbon dioxide tension $\left(\mathrm{PaCO}_{2}\right)$. The maximal workload and heart rate achieved were compared with the predicted normal values given by JONES [16]. At end-exercise the subjective degree of dyspnoea was rated on a modified Borg scale [17]. The incremental cycle ergometer test was performed 2 weeks before training started and repeated one day after its termination to evaluate the effects of training on exercise performance.

Inspiratory muscle strength. Sniff-assessed maximal oesophageal and transdiaphragmatic pressure values served as parameters for global inspiratory muscle strength and diaphragmatic strength, respectively [18, 19]. To measure oesophageal (Poes) and transdiaphragmatic pressure (Pdi), a flexible, distilled water-perfused, double-lumen catheter was used. The catheter-pressure transducer-system was described in detail previously [20]. Pdi was obtained by subtracting Poes from gastric pressure (Pga). Poes, Pga and Pdi obtained during the sniff manoeuvres were stored in a PC-AT (with a sampling rate of $20 \mathrm{~Hz}$ and resolution of 12 bits). When a plateau of sniff Poes and Pdi was reached (usually within five sniffs), an extra 10 maximal sniffs were carried out to ensure no further increase. The highest Poes and Pdi values were then selected for analysis. Sniff trials were performed at resting end-expiration. Poes and Pga were arbitrarily assigned zero at the start of each sniff; therefore, only pressure changes relative to the initial level were recorded.

Inspiratory muscle endurance. To determine inspiratory muscle endurance, a device similar to that proposed by NiCKERSON and KeENS [21] was used. Subjects inspired through a two-way valve, the inspiratory part of which was connected to a chamber and plunger to which weights could be added externally (Segadat, Vienna, Austria). The duration for which the patient could inhale against a certain weight was used as an index of endurance. A certain weight was selected for each patient so that he/she had to generate a Pdi $70 \%$ of the maximal sniff-assessed Pdi with each inspiration. Pdi was continuously displayed on the screen of a PC-AT 
in front of the patients with the $70 \%$ of Pdimax marked. Poes and Pga were not controlled during the resistive breathing runs, so that the patients could use predominantly the rib cage muscles or the diaphragm to generate the target Pdi. Breathing frequency $\left(f_{R}\right)$ was held constant throughout, and corresponded to the patient's resting $f \mathrm{R}$, which was assessed during $10 \mathrm{~min}$ before the test began. Two different sounds produced by the computer were used as an audible cue for maintaining $f \mathrm{R}$; inspiratory and expiratory times were adapted according to the patient's duty cycle. Resistive breathing manoeuvres were stopped when the patients could not generate target Pdi for three consecutive breaths. Immediately after the fatigue run, the patients performed 10 sniff manoeuvres, and the highest Poes and Pdi values were selected for comparison with baseline.

The test for assessing inspiratory muscle strength and endurance was performed one day before training started and repeated one day after its cessation.

\section{Training protocol}

Cycle ergometer training (CET) consisted of exercise on a calibrated cycle ergometer under the supervision of a physical therapist. Patients exercised 4 days a week (Monday, Tuesday, Thursday and Friday) for 8 weeks. The daily training session lasted $20 \mathrm{~min}$ at the beginning, and was increased after 3 weeks to 25 and after 6 weeks to $30 \mathrm{~min}$. Training intensity (TI) was defined by a training heart rate (THR) which was continuously monitored during each session by a heart rate monitor. Workload could be increased, if necessary, to maintain a constant TI throughout the 8 week period. Patients were allowed to exercise at a range from THR to THR +10 beats. THR was calculated as $60 \%$ of the maximal heart rate reserve by the formula [22]:

$$
\text { (maximal HR - resting } \mathrm{HR}) \times 0.6 \text { + resting } \mathrm{HR}
$$

Maximal heart rate was derived from the incremental cycle ergometer test, performed two weeks before training began.

Inspiratory muscle training. In addition to CET, 30 of the 60 patients (20 males and 10 females) participated in a specific training programme for the inspiratory muscles. IMT consisted of strength and endurance training. For strength training, patients had to perform daily 12 maximal static inspiratory efforts against an almost completely occluded resistance at residual volume, as described by Black and HyatT [23]. A 15 s interval between the manoeuvres was allowed, each lasting $\geq 2 \mathrm{~s}$. The pressure values generated were measured with a \pm 300 $\mathrm{cmH}_{2} \mathrm{O}$ differential pressure transducer (model $142 \mathrm{PC}$, Honeywell, Freeport, Ill, USA) and displayed in arbitrary units as a vertical beam on the screen of a PC/AT. One day before training began, the first 12 of these manoeuvres were performed by the patients to determine the maximal achievable pressure. During the 8 week training period they had to generate, with each maximal contraction, a pressure of at least $80 \%$ of this predetermined value. The pressure target was marked on the screen of the PC in front of the patient. When the generated pressure exceeded this target three times or more during one session, the pressure target was readjusted.

For endurance training, the same kind of pressure threshold breathing device was used to evaluate endurance. During the 8 week training, patients had to daily breathe for $10 \mathrm{~min}$ at a given inspiratory pressure, namely $70 \%$ of the maximal sniff-assessed Pdi. Expiration was unloaded. The appropriate weight was determined within the scope of the tests for measuring inspiratory muscle endurance one day before training started. If the patient's endurance time was less than $10 \mathrm{~min}$, the weight against which he had to train was reduced, so that he had to generate a pressure only $60 \%$ of the maximal sniff Pdi. During training, the weight was increased every 2 weeks by $5-10 \%$ of the original weight. At the end of the 8 week training programme, the patients had to breathe on average against a weight $25 \%$ higher than the initial weight.

The manoeuvres for IMT were performed at least 30 min after CET. Strength training was always performed first, and followed by endurance training after at least $10 \mathrm{~min}$.

\section{Data analysis}

Breathing pattern was examined using the familiar Hey plot: $\dot{V}_{E}$ was plotted against VT [24]. Statistical comparisons within a group and between groups were performed with a paired and unpaired t-test, respectively. A two-tailed p-value of less than 0.05 was considered to indicate statistical significance. Values throughout the text and tables are expressed as means \pm SD.

\section{Results}

Of the 60 patients who were initially included in the study, 42 completed the whole training programme. Most patients dropped out because of exacerbation of COPD or insufficient compliance. When these were compared with those who completed the study, no significant differences could be detected in their physical characteristics, lung function parameters, exercise performance or inspiratory muscle function. Furthermore, the number of drop-outs was similar in the two training groups. The anthropomorphic and resting pulmonary function data from the remaining 42 patients are shown in table 1. Twenty one of the 42 patients (Group 1) (12 males and 9 females) performed the CET combined with IMT; the remaining 21 (Group 2) (10 males and 11 females) performed the CET programme only. There were no significant differences regarding physical characteristics and pulmonary function indices. No significant changes of the pulmonary function indices were found in either group after training. 
Table 1 - Physical characteristics, resting lung function data and blood gas values in the two study groups

\begin{tabular}{llcc}
\hline & & Group 1 & Group 2 \\
& & $\mathrm{CET}+\mathrm{IMT}$ & $\mathrm{CET}$ \\
& & $55 \pm 21$ & $\mathrm{n}=21$ \\
\hline Age & $\mathrm{yrs}$ & $168 \pm 8$ & $57 \pm 6$ \\
$\mathrm{Height}$ & $\mathrm{cm}$ & $72.3 \pm 9.4$ & $166 \pm 8$ \\
Weight & $\mathrm{kg}$ & $3.03 \pm 0.89$ & $70.8 \pm 10.6$ \\
$\mathrm{FVC}$ & $l$ & $81 \pm 18$ & $3.12 \pm 0.67$ \\
& $\%$ pred & $1.31 \pm 0.52$ & $83 \pm 18$ \\
$\mathrm{FEV}_{1}$ & $l$ & $44 \pm 19$ & $1.34 \pm 0.44$ \\
& $\%$ pred & $44 \pm 15$ & $48 \pm 17$ \\
$\mathrm{FEV}_{1} / \mathrm{FVC}$ & $\%$ & $6.9 \pm 1.6$ & $43 \pm 14$ \\
$\mathrm{TLC}$ & $l$ & $129 \pm 20$ & $6.4 \pm 1.1$ \\
& $\%$ pred & $162 \pm 49$ & $121 \pm 19$ \\
$\mathrm{FRC}$ & $\%$ pred & $206 \pm 55$ & $137 \pm 31$ \\
$\mathrm{RV}$ & $\%$ pred & $0.32 \pm 0.22$ & $190 \pm 51$ \\
$\mathrm{Raw}$ & $\mathrm{kPa} \cdot l^{-1} \cdot \mathrm{s}$ & $9.1 \pm 1.2$ & $0.30 \pm 0.19$ \\
$\mathrm{PaO}_{2}$ & $\mathrm{kPa}$ & $5.6 \pm 0.8$ & $9.4 \pm 1.4$ \\
$\mathrm{PaCO}_{2}$ & $\mathrm{kPa}$ & $5.3 \pm 0.9$ \\
\hline
\end{tabular}

Data are presented as mean \pm SD. CET: cycle ergometer training; IMT: inspiratory muscle training; FVC: forced vital capacity; $\mathrm{FEV}_{1}$ : forced expiratory volume in one second; TLC: total lung capacity; FRC: functional residual capacity; RV: residual volume; Raw: mean airway resistance; $\mathrm{PaO}_{2}$ : arterial oxygen tension; $\mathrm{PaCO}_{2}$ : arterial carbon dioxide tension; \% pred: percentage of predicted value: Sources of predicted values are given in the text.

\section{Effect of training on inspiratory muscle performance}

Baseline inspiratory muscle function data were similar in both groups (table 2). This table further indicates that patients who had both IMT and CET showed a significant increase in global inspiratory muscle strength and diaphragmatic strength. Their inspiratory muscle endurance time also increased significantly. Conversely, these parameters remained unchanged in Group 2. For the Group 1 patients, the maximal sniff-induced Poes and Pdi, evaluated immediately after the resistive breathing test, were $41.2 \pm 15.0 \mathrm{cmH}_{2} \mathrm{O}$ ( $71 \%$ of control) and $60.8 \pm 18.7$ $\mathrm{cmH}_{2} \mathrm{O}(76 \%$ of control) before training, and $59.2 \pm 18.9$ $\mathrm{cmH}_{2} \mathrm{O}\left(74 \%\right.$ of control) and $77.5 \pm 25.1 \mathrm{cmH}_{2} \mathrm{O}(70 \%$ of control) after training, respectively.

For the Group 2 patients, with exhaustion the mean Poes, max and mean Pdi,max were $48.1 \pm 15.4 \mathrm{cmH}_{2} \mathrm{O}$ (77\% of control) and $66.3 \pm 16.0 \mathrm{cmH}_{2} \mathrm{O}(76 \%$ of control) before training, and $47.4 \pm 16.9 \mathrm{cmH}_{2} \mathrm{O}(72 \%$ of control) and $68.2 \pm 16.6 \mathrm{cmH}_{2} \mathrm{O}(75 \%$ of control) after training, respectively. This shows that the resistive breathing manoeuvres caused a similar degree of exhaustion, before and after training in both groups.

\section{Maximal exercise data}

The data of the exercise tests before and after training are shown in table 4 . Both patient groups showed a significant increase in maximal power output (Wmax) and maximal oxygen uptake $\left(\dot{\mathrm{V}}_{2} \mathrm{max}\right)$ after training. However, this improvement was significantly greater in Group 1 (fig. 1). Furthermore, Group 1 patients could improve their maximal exercise ventilation ( $\dot{V}_{\text {Emax }}$ ) and maximal tidal volume (VTmax) significantly. No such changes could be observed in Group 2. Both before and after training, $\dot{\mathrm{V}} \mathrm{E}$ was not significantly different between the two groups at comparable levels of power output (fig. 2). When analysing the breathing pattern using the Heyplot, we again observed no significant differences between the two groups. The VT values were similar in the two

Table 2. - Inspiratory muscle function parameters in the two study groups

\begin{tabular}{|c|c|c|c|c|}
\hline & \multicolumn{2}{|c|}{ Group 1 CET + IMT } & \multicolumn{2}{|c|}{ Group 2 CET } \\
\hline & Pret & Post $\dagger$ & Pret & Post $\dagger$ \\
\hline Poes, max $\mathrm{cmH}_{2} \mathrm{O}$ & $57.9 \pm 19.3$ & $80.8 \pm 26.6^{* *}$ & $62.3 \pm 20.9$ & $65.4 \pm 22.8^{+}$ \\
\hline $\mathrm{Pdi}, \mathrm{max} \quad \mathrm{cmH}_{2} \mathrm{O}$ & $80.5 \pm 24.4$ & $110.8 \pm 32.2 * *$ & $87.8 \pm 18.9$ & $90.9 \pm 21.5^{+}$ \\
\hline Tlim $\min$ & $12.0 \pm 6.7$ & $16.5 \pm 7.4 * *$ & $12.2 \pm 6.2$ & $12.3 \pm 7.2$ \\
\hline
\end{tabular}

Data are presented as mean \pm SD. CET: cycle ergometer training; IMT: inspiratory muscle training; + : pre- and post-training values; Poes,max: maximal sniff-assessed oesophageal pressure; Pdi,max: maximal transdiaphragmatic pressure; Tlim: endurance time. **: $\mathrm{p}<0.001$ vs baseline value; ${ }^{+}: \mathrm{p}<0.05$ vs Group 1.

Table 3. - Maximal exercise data in the two study groups

\begin{tabular}{|c|c|c|c|c|c|}
\hline & & \multicolumn{2}{|c|}{ Group 1 CET + IMT } & \multicolumn{2}{|c|}{ Group 2 CET } \\
\hline & & Pre† & Post $\dagger$ & Pre† & Post $\dagger$ \\
\hline \multirow{2}{*}{$\overline{\mathrm{Vo}_{2} \max }$} & $l \cdot \mathrm{min}^{-1}$ & $1.09 \pm 0.37$ & $1.32 \pm 0.41 * *$ & $1.14 \pm 0.28$ & $1.24 \pm 0.35^{*}$ \\
\hline & $\%$ pred & $63 \pm 12$ & $76 \pm 14 * *$ & $66 \pm 11$ & $73 \pm 14 *$ \\
\hline \multirow[t]{2}{*}{ Wmax } & W & $80.4 \pm 31.6$ & $98.8 \pm 37.9 * *$ & $83.2 \pm 27.1$ & $92.8 \pm 32.7 *$ \\
\hline & $\%$ pred & $58 \pm 13$ & $73 \pm 15^{* *}$ & $60 \pm 12$ & $67 \pm 12^{*}$ \\
\hline \multirow[t]{2}{*}{ HRmax } & beats. $\min ^{-1}$ & $135 \pm 13$ & $146 \pm 13 * *$ & $138 \pm 15$ & $136 \pm 13$ \\
\hline & $\%$ pred & $77 \pm 7$ & $83 \pm 9 * *$ & $80 \pm 8$ & $78 \pm 8$ \\
\hline$\dot{V}$ emax & $l \cdot \mathrm{min}^{-1}$ & $47.6 \pm 15.3$ & $54.8 \pm 16.9 * *$ & $48.5 \pm 11.9$ & $48.4 \pm 0.5$ \\
\hline VTmax & $l$ & $1.41 \pm 0.39$ & $1.60 \pm 0.44 * *$ & $1.42 \pm 0.41$ & $1.43 \pm 0.5$ \\
\hline $\mathrm{PaO}_{2}$ & $\mathrm{kPa}$ & $8.7 \pm 1.2$ & $8.8 \pm 1.2$ & $8.9 \pm 1.2$ & $8.9 \pm 1.3$ \\
\hline $\mathrm{PaCO}_{2}$ & $\mathrm{kPa}$ & $5.3 \pm 0.8$ & $5.0 \pm 1.0$ & $5.2 \pm 0.8$ & $5.1 \pm 1.0$ \\
\hline
\end{tabular}

Data are presented as mean \pm SD. $\dagger$ : pre- and post-training values; $\dot{V}_{2}$ max: maximal oxygen uptake; Wmax: maximal power output; HRmax: maximal heart rate; VEmax: maximal minute ventilation; VTmax: maximal tidal volume. For further abbreviations see legend to table 1 . Sources of predicted values are given in the text. *: $\mathrm{p}<0.001$ vs pre-training values; *: $\mathrm{p}<0.05$ vs pre-training values. 


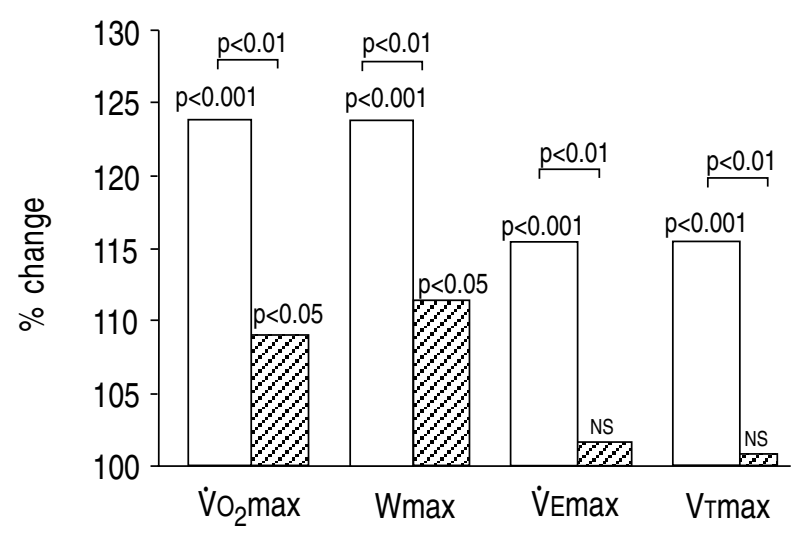

Fig. 1. - Percentage increase of maximal exercise data induced by training in the two study groups. $\dot{\mathrm{V}}_{\mathrm{o}}$ max: maximal oxygen uptake; Wmax: maximal power output; VEmax: maximal exercise ventilation; VTmax: maximal tidal volume; NS: nonsignificant. Statistical significance is indicated both between and within groups. $\square$ : Group 1, cycle ergometer training + inspiratory muscle training; $\square$ : Group 2 , cycle ergometer training alone.

groups at comparable levels of $\dot{\mathrm{V}}$, before and after training (fig. 3). Although, after training, the Group 1 patients achieved higher VEmax and Wmax values than the Group 2 patients (table 1), the rating of dyspnoea at end-exercise was similar in both groups (7.2 \pm 1.7 vs $7.0 \pm 1.4$ units).

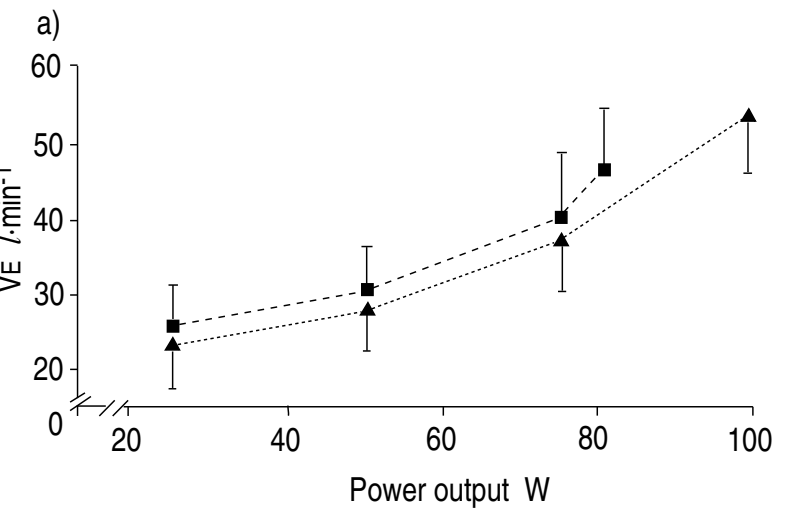

b)

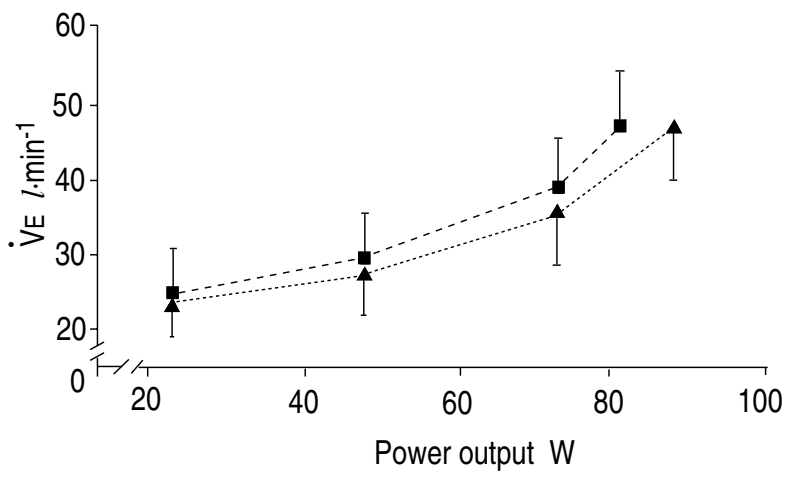

Fig. 2. - Group mean values of minute ventilation (VE) versus power output of 25,50,75 W and at end-exercise before and after training for: a) the Group 1 patients; and b) the Group 2 patients. Group 1: cycle ergometer training + inspiratory muscle training; Group 2: cycle ergometer training. Bars indicate \pm SD. $\mathbf{\square}$ : before training; $\boldsymbol{\Delta}$ : after training

\section{Discussion}

Our study has yielded the following results: 1) In COPD patients, a rehabilitation programme consisting of IMT and CET improves inspiratory muscle performance, whereas CET alone does not affect the functioning of these muscles; and 2) IMT combined with CET, and CET alone improve exercise performance. This improvement, however, is significantly greater when IMT is included in the programme.

In COPD, exercise tolerance is believed to be limited both by lung mechanics and respiratory muscle performance. Therefore, methods to improve respiratory muscle function have received considerable attention, such as pharmacological therapy, oxygen, nutrition, rest and training [4]. But the role of specific IMT in patients with COPD remains uncertain.

Respiratory muscles exhibit similar adaptions to training as other skeletal muscles, provided that the training follows the basic training principles for any striated muscle, with regard to intensity, duration of the stimulus and the specificity of the training [25]. It has been shown several times that IMT has a beneficial effect on exercise performance in COPD patients. Depending on which tests were used to evaluate performance, improvements could be demonstrated in maximal exercise
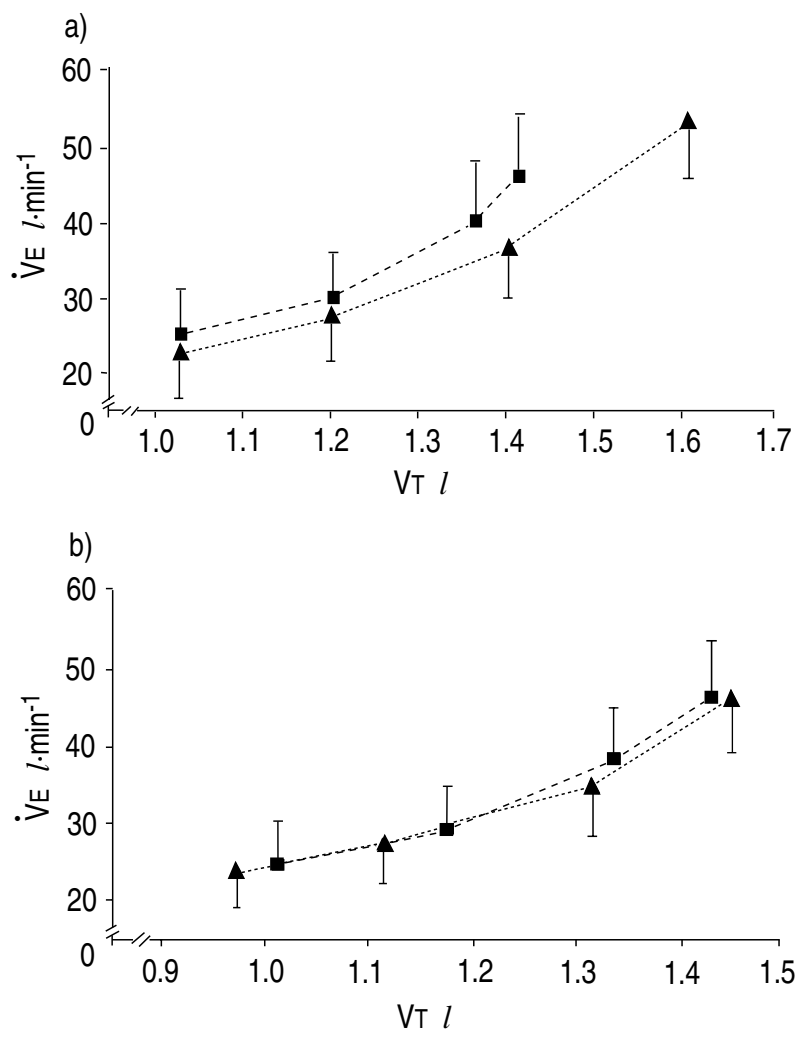

Fig. 3. - Group mean values of minute ventilation $\left(\dot{V}_{\mathrm{E}}\right)$ versus tidal volume (VT) at power output of $25,50,75 \mathrm{~W}$ and at end-exercise before and after training for: a) the Group 1 patients; and b) the Group 2 patients. Group 1: cycle ergometer training + inspiratory muscle training; Group 2: cycle ergometer training. Bars indicate $\pm \mathrm{SD}$. $\mathbf{\square}$ : before training; $\mathbf{\Delta}$ : after training. 
ventilation and oxygen uptake measured by an incremental cycle ergometer test $[5,7]$, in the endurance time whilst cycling at a constant submaximal work load [5-7], and in the 12 min walking distance [6,7]. In a recent paper, IMT in addition to pulmonary rehabilitation was shown to have an extra beneficial effect on exercise performance evaluated with the 12 min walking distance [26]. In another paper, IMT combined with general exercise reconditioning provided greater improvement in exercise tolerance than general exercise reconditioning alone [27]. In that study, the endurance time whilst cycling at a constant submaximal workload and the 12 min walking test were used as parameters. Other authors, however, could not demonstrate any beneficial effects of IMT on exercise performance [28, 29]. Because of these controversial results, the positive effects of IMT are considered to be uncertain [30,31], and it has been pointed out that, at present, IMT cannot be recommended as part of the routine management of COPD patients [32].

The results of our study have demonstrated, however, that IMT, when combined with CET, improves exercise capacity significantly more than does CET alone. When WEINER et al. [27] compared the effects of IMT combined with general exercise reconditioning with that of general exercise reconditioning alone, they also found greater improvements in cycle ergometer performance when IMT was included. In that study, the patients' endurance time, while cycling at a constant submaximal workload until exhaustion, served as parameter for exercise tolerance. They did not evaluate exercise performance by incremental cycle ergometer tests. Incremental or progressive exercise tests are now being used increasingly in clinical evaluation of ventilatory control and exercise tolerance. The choice of progressive exercise in our study could evaluate the effects of combined IMT and CET on rapidly changing ventilatory variables and maximal exercise performance. WeINER et al. [27] did not change the intensity of general exercise training after the first month of training until the end (after 6 months). Therefore, one could argue that the training intensity in that study was too low during the last months of the training period, which might have influenced the results. In our study, the intensity of CET remained constant and sufficiently high throughout the whole training period. The results of our study clearly demonstrate that it makes sense to offer COPD patients IMT in addition to CET.

We compared the effects of IMT combined with CET with those of CET alone, but did not evaluate the effects of a sole IMT regimen. This was for two reasons. Firstly, it is already well-established that general exercise training is a cornerstone of rehabilitation programmes for patients with COPD [2, 4]; therefore, we did not want to withhold this from our patients. Secondly, IMT for the purpose of improving exercise tolerance violates the principle of training specifity - that the training technique should mirror the activity in which improvement is desired - in this case whole body exercise. Therefore, we have chosen the combined IMT and CET programme and refrained from performing IMT alone. We have also refrained from evaluating the effects of a training programme consisting of sham IMT and CET. Since both CET and IMT increase the mechanical load on the inspiratory muscles, we were mainly concerned with whether IMT, when added to CET, is hazardous by causing "overwork weakness" of the respiratory muscles. A sham IMT and CET programme would not provide us with an answer to this question.

Maximal power output, maximal oxygen uptake and maximal exercise ventilation were the parameters for exercise capacity. They increased in both patient groups, but significantly more in the group with additional IMT. Several factors may account for this phenomenon: 1) Exercise-induced $\dot{V}_{E}$ increase places a substantial load on the ventilatory muscles. During ventilatory stress the respiratory muscles produce lactate [33]. By improving performance, these muscles might produce less lactate during exercise-induced ventilatory stress. 2) The conditioning of the respiratory muscles might enable patients to tolerate higher $\mathrm{PaCO}_{2}$ levels. 3) Furthermore, improved inspiratory muscle performance might increase ventilatory efficacy for $\mathrm{CO}_{2}$ clearance (physiological dead space/tidal volume $(\mathrm{VD} / \mathrm{VT})$ ) by increasing tidal volume. Since: $\dot{\mathrm{V}}_{\mathrm{E}}=\mathrm{K} \times$ carbon dioxide output $\left(\mathrm{VCO}_{2}\right) /\left[\mathrm{PaCO}_{2} \times(1-\mathrm{VD} / \mathrm{VT})\right]$, (where $\mathrm{K}$ is a constant), a reduction of lactic acidosis by the respiratory muscles, an increase in $\mathrm{PaCO}_{2}$, or an increased $\mathrm{CO}_{2}$ clearance by a reduction of $\mathrm{Vd} / \mathrm{V}_{\mathrm{T}}$ will reduce the ventilatory requirement for a given level of work. In our study, however, the ventilatory requirements were similar in both groups at comparable levels of power output, and this was true before and after training. In addition, when analysing the breathing pattern by plotting $\dot{\mathrm{V}}_{\mathrm{E}}$ against $\mathrm{V}_{\mathrm{T}}$, we found that the $\mathrm{V}_{\mathrm{T}}$ values obtained at comparable levels of VE were similar in both groups. Therefore, the extra beneficial effect of IMT in our patients cannot be explained by the above-mentioned factors. Since, $\dot{V}_{E}$ was similar in both groups at equivalent workloads, and patients with IMT achieved a higher maximal power output than those without IMT, patients with IMT obtained a higher maximal $\dot{\mathrm{V}} \mathrm{E}$ than those without IMT. The $V_{T}$ at peak exercise was also higher in the IMT group. Although patients with IMT exhibited higher VEmax and VTmax values, the intensity of dyspnoea was similar in both groups. Dyspnoea is closely correlated with respiratory effort sensation [34]. Inspiratory flow rate, $\mathrm{V}_{\mathrm{T}}$, the pressure generated during inspiration and the capacity of the respiratory muscle to generate pressure all determine the intensity of effort [17]. Our patients with IMT could significantly increase their maximal sniff-induced Poes and Pdi values, which are valid indices for global inspiratory muscle strength and diaphragmatic strength, respectively. The improved capacity of their respiratory muscles to generate pressure may, therefore, enable them to tolerate a higher exercise ventilation and, thus, achieve a higher workload.

Since none of our patients had a resting $\mathrm{PaCO}_{2}$ of greater than $6.0 \mathrm{kPa}$, our results may not be applicable to $\mathrm{COPD}$ patients with $\mathrm{CO}_{2}$ retention. But they clearly demonstrate that IMT, in combination with CET, does not cause "overwork weakness" of the inspiratory 
muscles in patients without $\mathrm{CO}_{2}$ retention, even when they have severe chronic airflow obstruction.

In summary, cycle ergometer training alone improves maximum exercise capacity, but not inspiratory muscle performance. Additional IMT improves inspiratory muscle strength and endurance, and enhances maximum exercise capacity significantly more than CET. Our results indicate that IMT, when performed in addition to cycle ergometer training, can be a useful part of pulmonary rehabilitation for COPD patients.

Acknowledgements: The authors thank B. Krenek for her skilful work as physiotherapist.

\section{References}

1. Decramer M. Pulmonary rehabilitation: art or science? Eur Respir J 1992; 5: 155-156.

2. Casaburi R, Patessio A, Ioli F, Zanaboni S, Donner CF, Wassermann K. Reductions in exercise lactic acidosis and ventilation as a result of exercise training in patients with obstructive lung disease. Am Rev Respir Dis 1991; 143: 9-18.

3. Carter R, Nicotra B, Clark L, et al. Exercise conditioning in the rehabilitation of patients with chronic obstructive pulmonary disease. Arch Phys Med Rehabil 1988; 69: 118-122.

4. Donner CF, Howard P. Pulmonary rehabilitation in chronic obstructive pulmonary disease (COPD) with recommendations for its use. Eur Respir J 1992; 5: 266-275.

5. Sonne LJ, Davis JA. Increased exercise performance in patients with severe COPD following inspiratory resistive training. Chest 1982; 81: 436-439.

6. Pardy RL, Rivington RN, Despas PJ, Macklem PT. Inspiratory muscle training compared with physiotherapy in patients with chronic airflow limitation. Am Rev Respir Dis 1981; 123: 421-425.

7. Belman MJ, Mittman Ch. Ventilatory muscle training improves exercise capacity in chronic obstructive pulmonary disease patients. Am Rev Respir Dis 1980; 121: 273-280.

8. Larson JL, Kim MJ, Sharp JT, Larson DA. Inspiratory muscle training with a pressure threshold breathing device in patients with chronic obstructive pulmonary disease. Am Rev Respir Dis 1988; 138: 689-696.

9. Smith PEM, Coakley JH, Edwards RHT. Respiratory muscle training in Duchenne's muscular dystrophy (letter). Muscle \& Nerve 1988; 11: 784.

10. Braun NMT, Faulkner J, Hughes RL, Roussos Ch, Sahgal V. When should respiratory muscles be exercised? Chest 1983; 84: 76-84.

11. NHLBI Workshop Summary. Respiratory muscle fatigue. Report of the Respiratory Muscle Fatigue Workshop Group. Am Rev Respir Dis 1990; 142: 474-480.

12. Similowski Th, Yan S, Gauthier AP, Macklem PT, Bellemare F. Contractile properties of the human diaphragm during chronic hyperinflation. $N$ Engl J Med 1991; 325: 917-923.

13. Dillard TA, Piantadosi S, Rajagapal KR. Determinants of maximum exercise capacity in patients with chronic airflow obstruction. Chest 1989; 96: 267-271.

14. American Thoracic Society. Evaluation of impairment/disability secondary to respiratory disorder. Am Rev Respir Dis 1986; 133: 1205-1209.
15. European Community for Steel and Coal. Standardized lung function testing. Eur Respir J 1993; 6 (Suppl. 16): 25-27.

16. Jones NL. The interpretation of stage 1 exercise test results. In: Jones NL, ed. Clinical Exercise Testing. London, W.B. Saunders Co., 1988; pp. 158-185.

17. Bradley TD, Chartrand DA, Fitting JW, Killian KJ, Grassino A. The relation of inspiratory effort sensation to fatiguing patterns of the diaphragm. Am Rev Respir Dis 1986; 134: 1119-1124.

18. Laroche CM, Mier AK, Moxham J, Green M. The value of sniff esophageal pressures in the assessment of global inspiratory muscle strength. Am Rev Respir Dis 1988; 138: 598-603.

19. Miller JM, Moxham J, Green M. The maximal sniff in the assessment of diaphragm function in man. Clin $\mathrm{Sci}$ 1985; 69: 91-96.

20. Wanke T, Schenz G, Zwick H, Popp W, Ritschka L, Flicker M. Dependence of maximal sniff-generated mouth and transdiaphragmatic pressures on lung volume. Thorax 1990; 45: 352-355.

21. Nickerson BG, Keens TG. Measuring ventilatory muscle endurance in humans as sustainable inspiratory pressure. J Appl Physiol: Respirat Environ Exercise Physiol 1982; 52: 768-772.

22. Karvonen M, Kentala K, Mustala O. The effects of training heart rate: a longitudinal study. Ann Med Exper Fenn 1957; 35: 307-315.

23. Black LF, Hyatt RE. Maximal respiratory pressures: normal values and relationship for age and sex. Am Rev Respir Dis 1969; 99: 696-702.

24. Hey EN, Lloyd BB, Cunningham DJC, Jukes MGM, Bolton DPG. Effects of various respiratory stimuli on the depth and frequency of breathing in man. Respir Physiol 1966; 1: 193-205.

25. Leith DE, Bradley M. Ventilatory muscle strength and endurance training. J Appl Physiol 1976; 41: 508-516.

26. Dekhuijzen PNR, Folgering HTM, van Herwaarden CLA. Target-flow inspiratory muscle training during pulmonary rehabilitation in patients with COPD. Chest 1991; 99: 128-133.

27. Weiner P, Azgad Y, Ganam R. Inspiratory muscle training combined with general exercise reconditioning in patients with COPD. Chest 1992; 102: 1351-1356.

28. Madsen F, Secher NH, Kay L, Kork-Jensen A, Rube N. Inspiratory resistance versus general physical training in patients with chronic obstructive pulmonary disease. Eur J Respir Dis 1985; 67: 167-176.

29. Chen H-I, Dukes R, Martin BJ. Inspiratory muscle training in patients with chronic obstructive pulmonary disease. Am Rev Respir Dis 1985; 131: 251-255.

30. Rampulla C, Ambrosino N. Inspiratory muscle training and rest in COPD patients. Eur Respir Rev 1991; 1: 490-497.

31. Fitting JW. Respiratory muscle fatigue limiting physical exercise? Eur Respir J 1991; 4: 103-108.

32. Goldstein RS. Ventilatory muscle training. Thorax 1993; 48: $1025-1033$.

33. Freedman S, Cooke NT, Moxham J. Production of lactic acid by respiratory muscles. Thorax 1983; 38: $50-54$.

34. Killian KJ, Gandevia SC, Summers E, Campbell EJM. Effect of increased lung volume on perception of breathlessness, effort and tension. J Appl Physiol: Respirat Environ Exercise Physiol 1984; 57: 686691. 